\title{
THERMAL STABILITY OF SERELY DEFORMED ALMG3 SHEETS
}

\author{
1'Ondřej HILŠER, 2Przemysław SNOPIŃSKI, '1Stanislav RUSZ, ${ }^{2}$ Tomasz TAŃSKI, \\ ${ }^{3}$ Wojciech MAZIARZ, ${ }^{3}$ Katarzyna STAN-GŁOWIŃSKA, ${ }^{1}$ Miroslav GREGER \\ ${ }^{1}$ VSB - Technical University of Ostrava, Ostrava, Czech Republic, EU, \\ ondrej.hilser@vsb.cz,stanislav.rusz@vsb.cz,miroslav.greger@vsb.cz
}

2Silesian University of Technology, Faculty of Mechanical Technology, Institute of Engineering Materials and Biomaterials, Gliwice,Poland,EU, przemyslaw.snopinski@polsl.pl, tomasz.tanski@polsl.pl

${ }^{3}$ Polish Academy of Science, Institute of Metallurgy and Materials Science, Department of Functional and Structural Materials, Krakow,Poland, EU, w.maziarz@imim.pl, k.stan@imim.pl

https://doi.org/10.37904/metal.2020.3491

\begin{abstract}
In this article a continuous severe plastic deformation (SPD) process entitled dual rolls equal channel extrusion (DRECE) for producing ultrafine-grained (UFG) microstructure of thin sheets is presented. The DRECE process combines conventional equal channel angular pressing (ECAP) process and continual CONFORM process, and it can be easily scaled for industrial use. Keeping constant both the cross section and the length of the severely deformed strip of sheet, the DRECE method promotes a refinement of the microstructure. The effect of post SPD annealing at different temperatures $\left(150^{\circ} \mathrm{C}, 180^{\circ} \mathrm{C}, 200^{\circ} \mathrm{C}, 250^{\circ} \mathrm{C}, 300^{\circ} \mathrm{C}\right.$ and $\left.350{ }^{\circ} \mathrm{C}\right)$ for 30 minutes on the stability of severely deformed microstructure of investigated AIMg3 aluminium alloy. The initial grain size was $\sim 7.9 \mu \mathrm{m}$ and was reduced to $6.8 \mu \mathrm{m}$ with maximum density of dislocation after 6 passes at room temperature, which were accompanied by the formation that is typical for low strain structures. The annealing treatment at temperatures lower than $180^{\circ} \mathrm{C}$ did $\mathrm{n}$ ot affe cted the microstructure significantly. A continuous grain growth occurred at higher temperatures $\left(180^{\circ} \mathrm{C}-300^{\circ} \mathrm{C}\right)$ due to the continuous recrystallization. A bimodal microstructure having a bimodal dislocation density distribution was obtained through the discontinuous recrystallization at $350^{\circ} \mathrm{C}$. The annealing led to some sort of bimodal grain mixture with the larger grains embedded in the severely deformed structure that provide and excellent combination of strength and ductility. Therefore, the DRECE process could be a promising industrial SPD method to continuously produce advanced construction materials with the advantages of energy and cost saving and high process efficiency.
\end{abstract}

Keywords: Aluminium alloy, severe plastic deformation, microstructure, EBSD, microhardness

\section{INTRODUCTION}

It is well known that metallic materials processed by severe plastic deformation have ultrafine-grained microstructure and exhibit enhanced utility properties [1-3]. Low thermal stability of the UFG microstructure due to the high energy accumulated during SPD is one of the problems associated with the application of UFG materials in industry [4-5].

During severe plastic deformation of Al-Mg based alloys, the mechanical properties and physical properties of the alloy change. The strength significantly increases, while ductility and deformation capacity decreases. The properties depend on the deformation. This is because the crystal lattice distorted in the deformed particles and the dislocation density increased [6-7]. 
In the deformed crystal lattice, the atomic distance is changed from the initial minimum energy state. Depending on the degree of displacement, the atoms get extra energy. Whereas, the distance among the atoms mostly determined by the deformation, it might say, that higher forming gets extra stored energy. During the cold SPD, the grain boundaries and the dislocations move on, while new dislocations are generated. The amount of dislocations is varied by the penetration or the tearing out of atomic-lines. The increased dislocation density prevents each other in the movement, following forming needs higher stress [8]. The materials aim to reach the lowest-energy state. The raising of the temperature provides the opportunity to start the necessary diffusion process. The diffusion (thermally activated process) is stimulated by the energy state difference between the initial and the final conditions. Result of the annealing, the internal stress, the hardness, and the strength values return to the state before forming. The amount of dislocations also returns to its equilibrium value. In the structure of the material new seeds appear, and solid-state crystallization occurs. Higher value of accumulated deformation energy causes higher stored energy, which results the decrease of the transition temperature [9].

In this article, the microstructure evolution of AIMg3 aluminium alloy processed by cold severe plastic deformation method DRECE (Dual Rolls Equal Channel Extrusion) [10] during annealing is investigated.

\section{INVESTIGATION PROCEDURES}

The investigation has been carried out on commercial AlMg3-H111 aluminium alloy sheets. The chemical composition of the alloy is given in Table 1.

Table 1 Chemical composition of investigated alloy AIMg3

\begin{tabular}{|c|c|c|c|c|c|c|c|c|c|}
\hline Element & $\mathbf{M g}$ & $\mathbf{S i}$ & $\mathbf{M n}$ & $\mathbf{F e}$ & $\mathbf{C r}$ & $\mathbf{C u}$ & $\mathbf{Z n}$ & $\mathbf{T i}$ & $\mathbf{A l}$ \\
\hline (wt. \%) & \multirow{2}{*}{$2.6-3.6$} & $\begin{array}{c}\text { max. } \\
0.40\end{array}$ & $\begin{array}{c}\text { max. } \\
0.50\end{array}$ & $\begin{array}{c}\max . \\
0.40\end{array}$ & $\begin{array}{c}\text { m.x. } \\
0.30\end{array}$ & $\begin{array}{c}\max . \\
0.10\end{array}$ & $\begin{array}{c}\max . \\
0.20\end{array}$ & $\begin{array}{c}\text { max. } \\
0.15\end{array}$ & rest. \\
\hline
\end{tabular}

The AlMg3 strips of sheet were lubricated by Li/Ca with addition of MoS2 grease. The strips were subjected to six passes through DRECE with a constant extrusion speed of $70 \mathrm{~mm} / \mathrm{min}$ and without changing the sample orientation between subsequent passes (deformation route A). A detailed description of DRECE forming method is given in [11].

To investigate the thermal stability of the microstructure after six passes, the samples were subjected to isothermal annealing at $150^{\circ} \mathrm{C}, 180^{\circ} \mathrm{C}, 200^{\circ} \mathrm{C}, 250^{\circ} \mathrm{C}, 300^{\circ} \mathrm{C}$ and $350^{\circ} \mathrm{C}$ respectively for $30 \mathrm{~min}$.

The microstructures were examined using a light microscope Axio Observer Z1. To reveal the grain size and morphology, the samples were mechanically ground and polished and then electrolytically etched using Barker's reagent. To study the microstructural evolution in a greater detail, the AIMg3 aluminum alloy samples were twin-jet electropolished in an electrolyte containing 20\% nitric acid and $80 \%$ methanol at a temperature of $-30^{\circ} \mathrm{C}$ and $20 \mathrm{~V}$ for $15 \mathrm{~s}$. Then, the grain structure was recorded by orientation imaging microscopy (OIM) using the electron backscattered diffraction (EBSD) technique integrated with a Zeiss Supra 35 Scanning Electron Microscope controlled and analyzed using OIM software.

\section{INVESTIGATION RESULTS}

Figure 1a show an optical micrograph of the investigated alloy in an initial state. It can be seen the typical microstructure built of equiaxed grains. The AlMg3 matrix coexist of a Mg in solid solution with fine dispersoids of $\mathrm{Mg}_{2} \mathrm{Si}$ and $\mathrm{Al}_{6} \mathrm{Mn}$ phases.

As compared with the initial state of microstructure (Figure 1a), the grain size is after six passes (Figure 1b) not reduced significantly. Areas of different crystallographic orientations inside individual grains are visible. Throughout subsequent passes, the grains remain equiaxed and almost constant in size. 


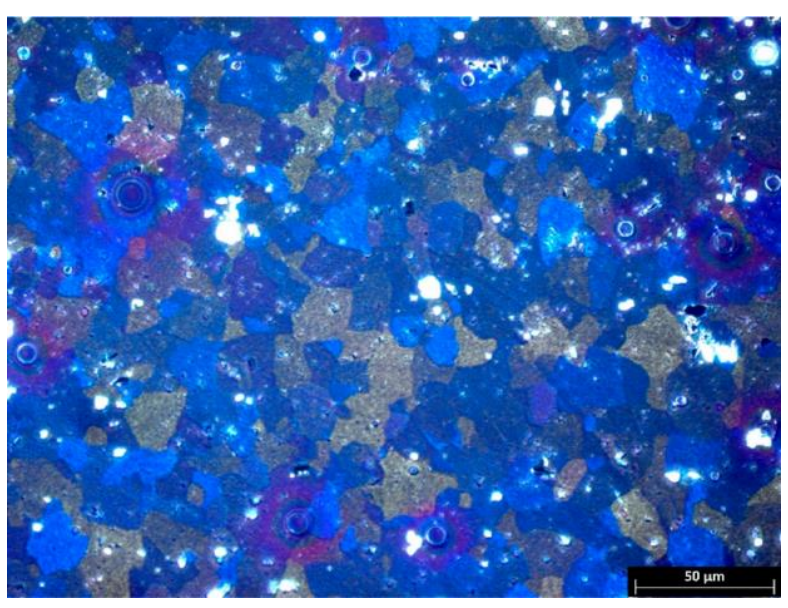

a)

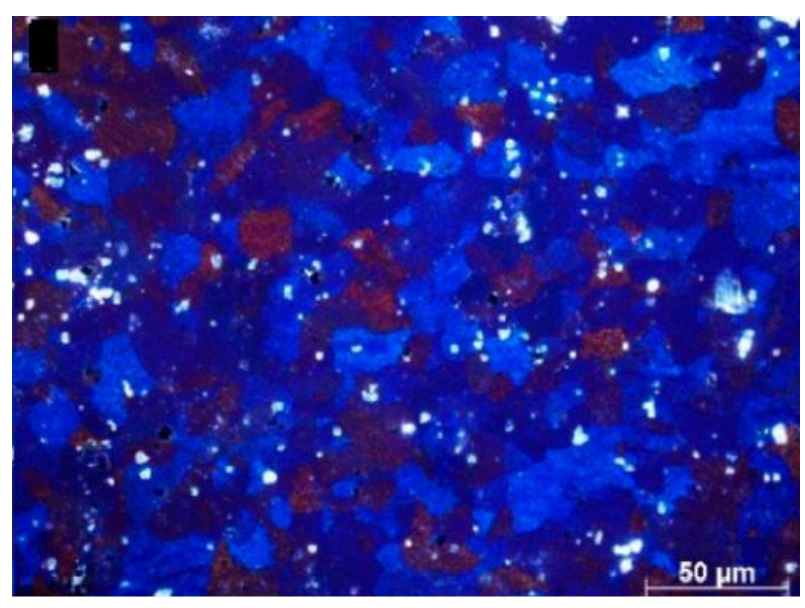

b)

Figure 1 Microstructure of AIMg3 alloy: Initial state (a) and after the six DRECE passes (b)

Figure 2 shows the EBSD colored inverse pole figure (IPF) maps of the AIMg3 alloy samples in an initial state and after six DRECE passes. The IPF image of the initial state sample (Figure 2a) demonstrates that the microstructure is composed of equiaxed grains. The measured average intercept length prior deformation is $\sim 7.9 \mu \mathrm{m}$. Figure $\mathbf{2} \mathbf{b}$ shows the microstructure of the sample subjected to six DRECE passes. In this state, the microstructure consists of grains covered with deformation bands having a low angle misorientation. This type of microstructure is typical for aluminum alloys subjected to low strains. The measured average intercept length after six DRECE passes slightly increases to $\sim 6.8 \mu \mathrm{m}$.

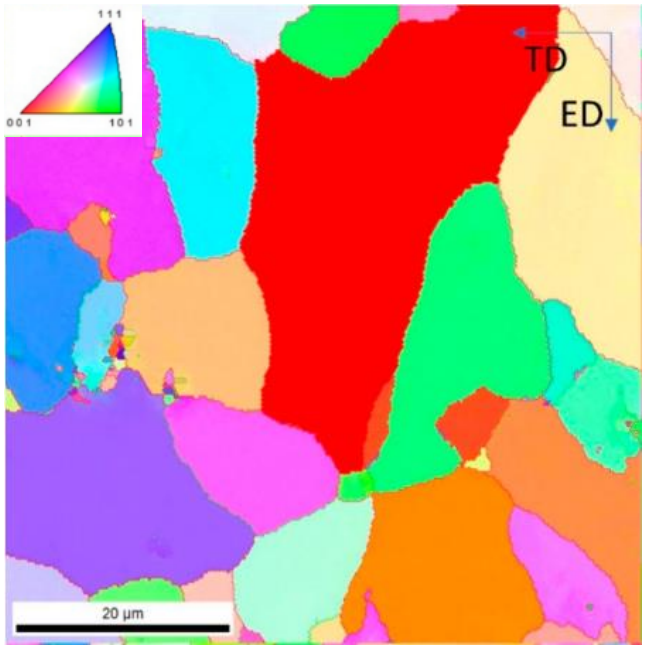

a)

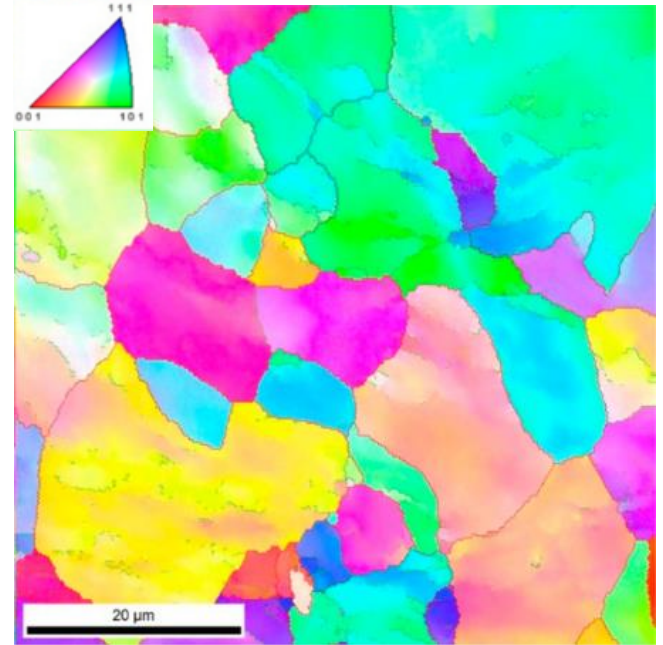

b)

Figure 2 IPF maps of AIMg3 alloy: Initial state (a) and after the six DRECE passes (b)

Light microscopy characterization of the grain microstructure of the AlMg3 alloy annealed at $150{ }^{\circ} \mathrm{C}, 180^{\circ} \mathrm{C}$, $200{ }^{\circ} \mathrm{C}, 250^{\circ} \mathrm{C}, 300{ }^{\circ} \mathrm{C}$ and $350^{\circ} \mathrm{C}$ is shown in Figure 3. It is apparent that during annealing at $150^{\circ} \mathrm{C}$, the process of recovery dominates (Figure $3 \mathbf{3}$ ). This is accompanied by a substantial dislocation density decrease from $7.6 \times 10^{14} \mathrm{~m}^{-2}$ in the as-deformed condition to $4.7 \times 10^{14} \mathrm{~m}^{-2}$, as shown in Figure 4a. During annealing at $180-300{ }^{\circ} \mathrm{C}$, the entire microstructure undergoes continuous recrystallization followed by grain growth (Figures $3 \mathrm{~b}-\mathrm{e}$ ). The first influence of annealing is visible in the sample annealed at $180^{\circ} \mathrm{C}$ (Figure $3 \mathrm{~b}$ ). In this condition, small recrystallized grains can be observed in the microstructure. The formation of the new grains 
is accompanied by a continuous dislocation density decrease to $4.4 \times 10^{14} \mathrm{~m}^{-2}$. The DRECE processed structure changes completely into coarse-grained and is approximately equiaxed with an increase in annealing temperature, obviously, as illustrated in Figure $\mathbf{3 e}$. This is followed by a gradual dislocation density decrease to $2.1 \times 10^{14} \mathrm{~m}^{-2}$. It is worth mentioning that for the sample annealed at $350^{\circ} \mathrm{C}$, the microstructure exhibit characteristics of both uniform coarsening and, in several places, of discontinuous recrystallization (Figure 3f). Thus, the obtained microstructure is bimodal, and the formation of the bimodal microstructure is accompanied by a slight dislocation density growth to $3.2 \times 10^{14} \mathrm{~m}^{-2}$. This is due to the presence of the new annealed microstructure that gives rise to compressive stress fields to the surrounding small-sized grains, resulting in a relatively lattice distortion and enhancing the dislocation density.

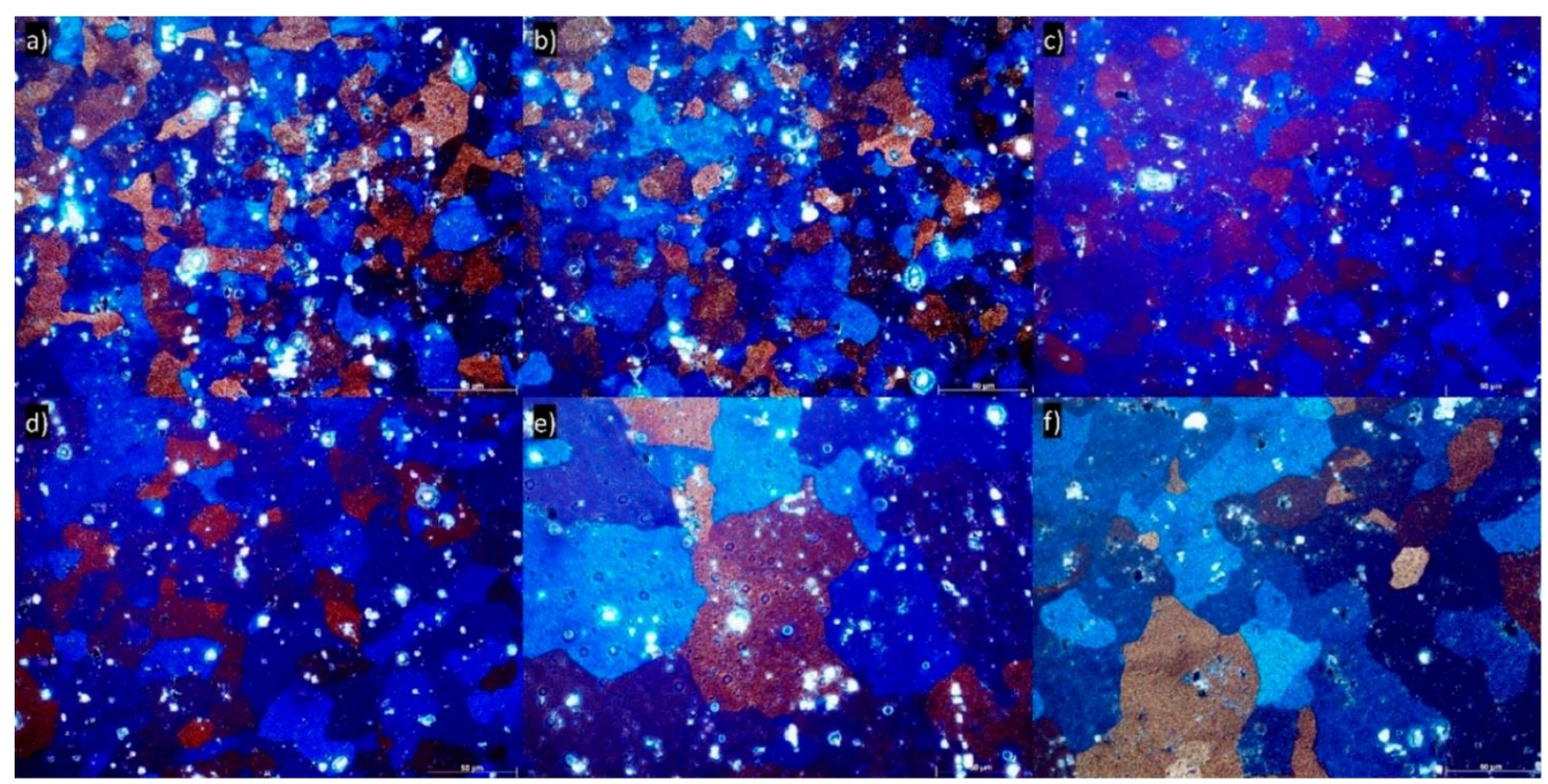

Figure 3 Microstructure of severely deformed AIMg3 alloy: annealed at $150^{\circ} \mathrm{C}$ (a); $180^{\circ} \mathrm{C}$ (b); $200^{\circ} \mathrm{C}$ (c); $250^{\circ} \mathrm{C}(\mathrm{d}), 300^{\circ} \mathrm{C}(\mathrm{e})$ and annealed at $350^{\circ} \mathrm{C}(\mathrm{f})$

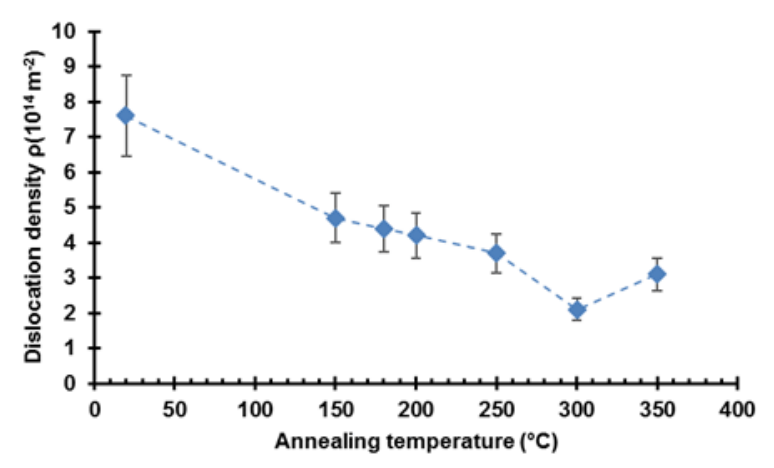

a)

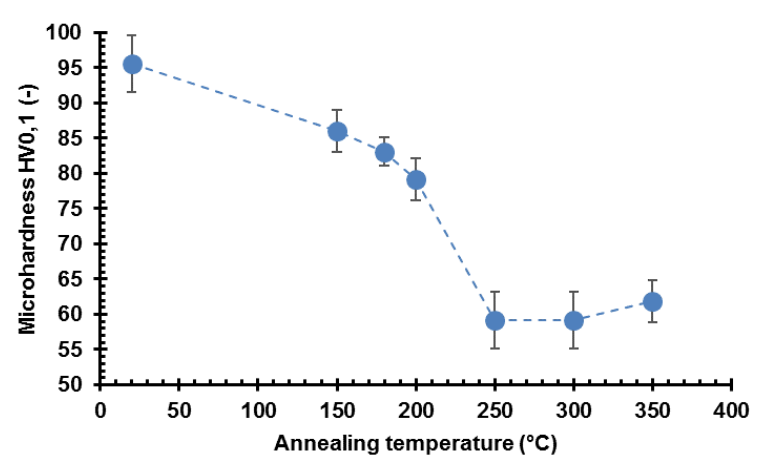

b)

Figure 4 Effect of annealing temperature on: Dislocation density (a) and Vickers microhardness (b)

It is evident, as shown in Figure $\mathbf{4 b}$, that the HV hardness decreases rapidly from an initial value of $\sim 95.6$ after six DRECE pass samples to $86.1 \mathrm{HV}$ after $30 \mathrm{~min}$ of isothermal annealing at $150{ }^{\circ} \mathrm{C}$. It is due to the ongoing recovery processes and is accompanied by a rapid dislocation density decrease. In this condition, the changes in the grain size are almost indistinguishable (Figure 3), and there is no evidence of the 
recrystallization processes. With an increase in an isothermal annealing temperature up to $180-200{ }^{\circ} \mathrm{C}$, hardness decreases slightly to $\sim 79.2 \mathrm{HV}$. The first evidence of the recrystallization and grain growth can be observed in the sample isothermally annealed at $250{ }^{\circ} \mathrm{C}$. This phenomenon is accompanied by a dislocation density reduction and hardness decrease to $\sim 59.2 \mathrm{HV}$. Annealing at $300^{\circ} \mathrm{C}$ causes a more significant grain growth. However, despite the observed microstructural changes, the hardness remains almost unchanged. When the material is subjected to isothermal annealing at $350{ }^{\circ} \mathrm{C}$, a slower softening rate is observed. In addition, the obtained microstructure is different: bimodal. This occurs because some grains have a much faster growth rate than others. Such a bimodal microstructure is inhomogeneous and is built of recrystallized and recovered grains and volumes with an unchanged distorted thermodynamically metastable structure; therefore, it combines the effects of the larger grains, which cause softening and the ultrafine grains that increase the mechanical properties.

\section{CONCLUSION}

In this article the evolution of microstructure, dislocation density and microhardness of commercial AIMg3 aluminium alloy, subjected to continuous severe plastic method, called DRECE, and subsequent annealing at different temperature were investigated. The main conclusions of presented research are summarized below.

The grain boundary maps for the EBSD data revealed that the fraction of low angle grain boundaries (LAGBs) increases along with an increasing number of DRECE passes. The DRECE process introduces a network of LAGBs, which may transform into HAGBs with further processing, especially if new shear planes will be activated.

The post-DRECE annealing of six passes of AIMg3 alloy samples at temperatures lower than $180{ }^{\circ} \mathrm{C}$ did not affect the microstructure significantly, indicating that recovery dominates. A continuous grain growth occurred at higher annealing temperatures $\left(180^{\circ} \mathrm{C}-300^{\circ} \mathrm{C}\right)$ due to the continuous recrystallization. A bimodal microstructure having a bimodal dislocation density distribution was obtained through the discontinuous recrystallization at $350^{\circ} \mathrm{C}$.

The hardness measurements of the annealed sample were consistent with the microstructural and XRD study. Grain coarsening led to a stepwise hardness decrease and resembled softening due to recovery before recrystallization. After annealing at the highest temperature $\left(350^{\circ} \mathrm{C}\right)$, the alloy microhardness significantly decreased to a value lower than that of the initial state alloy.

The difference in softening behavior reported in this study as a function of increasing annealing temperature is in line with competitive recovery-recrystallization kinetics, where a lower isothermal annealing temperature results in a gradual hardness decrease and resembled softening due to recovery, while at higher temperatures where recrystallization processes arise quickly, softening is faster.

\section{ACKNOWLEDGEMENTS}

The article presents the results obtained during the project MOBILITY no. 8JPL19035 and SP2020/106, entitled: "Research and Development of Modern Technologies of Welding, Forming and Surface Treatment Including Production Process Control”.

\section{REFERENCES}

[1] HU, J., KULAGIN, R., IVANISENKO, Y., BARETZKY, B., ZHANG, H. Finite element modeling of Conform-HPTE process for a continuous severe plastic deformation path. Journal of Manufacturing Processes. 2020, vol. 55, pp. 373-380.

[2] VISHNU, P., RAJ MOHAN, R., SANGEETHAA, K., RAGHURAMAN, S., VENKATRAMAN, R. Areview on processing of aluminium and its alloy through Equal Channel Angular Pressing die. Materials Today: Proceedings 2020, vol. 21, pp. 212-222. 
[3] HA, T., MURUDKAR, R., HARTWIG, K. T., WELO, T., RINGEN, G., WANG, J. A feasibility study of continuous grain refinement of sheet metal. Procedia Manufacturing 2020, vol. 48, pp. 379-387.

[4] BAGHERPOUR, E., MORTEZAEI, S., EBRAHIMI, R., MIYAMOTO, H., QODS, F. On the production of severely deformed workpieces in large scales: A step towards industralization. Journal of Metals 2019, vol. 71, no. 12, pp. 4424-4435.

[5] YU, H., TIEU, A. K., LU, C., LIU, X., LIU, M., GODBOLE, A., KONG, C., QIN, Q. A new insight into ductile fracture of ultrafine-grained Al-Mg alloys. Scientific Reports 2015, vol. 5, pp. 1-9.

[6] MORRIS, D. G., MUŇOZ-MORRIS, M. A. Microstructure of severely deformed Al-3Mg and its evolution during annealing. Acta Materialia. 2002 vol. 50, no. 16, pp. 4047-4060.

[7] BÉRES, G., DUGÁR, Z., KIS, D., HANSÁGHY, P. Examination of thermodynamic realignments of metals and metal alloys, by DMTA technique. Materials Science Forum 2015, vol. 812, pp. 291-296.

[8] YU, C. Y., SUN, P. L., KAO, P. W., CHANG, C. P. Evolution of microstructure during annealing of a severely deformed aluminium. Materials Science and Engineering A 2004, vol. 366, no. 2, pp. 310-317.

[9] IVANOV, K. V., OVCHARENKO, V. E. Structual features of ultrafine-grained aluminium processed thriugh accumulative roll bonding providing improved mechanical properties and thermal stability. Materials Science and Engineering A 2020, vol. 775, pp. 1-9.

[10] KOWALCZYK, K., JABLOŃSKA, M., RUSZ, S., BEDNARCZYK, I. Influence of the DRECE process of severe plastic deformation on the mechanical properties of the ultra-low carbon interstitial free steel. Archives of Metallurgy and Materials. 2018, vol. 63, no. 4, pp. 2095-2100.

[11] SNOPIŃSKI, P., TAŃSKI, T., GOŁOMBEK, K., RUSZ, S., HILŠER, O., DONIČ, T., NUCKOWSKI, P. M., BENEDYK, M. Strengthening of AA5754 aluminium alloy by DRECE process followed by annealing response investigation. Materials. 2020 vol. 13, no. 2, pp. 1-14. 